\title{
Formulation and evaluation of herbal microsponge by using enicostemma axillare leaf
} ethanolic extract

\author{
Velmurugan $\mathrm{T}^{1 *}$, Muthu Lakshmi $\mathrm{T}^{2}$, Sundararajan ${ }^{3}$, Santhasheela ${ }^{3}$, Reeta Vijayarani ${ }^{4}$ \\ ${ }^{1}$ Department of Pharmaceutics, Associate Professor, Mohamed Sathak AJ College of \\ Pharmacy, Sholinganallur, Chennai, Tamil Nadu, India \\ ${ }^{2}$ Department of Pharmacognosy, College of Pharmacy, Madras Medical College, Chennai, \\ Tamil Nadu, India \\ ${ }^{3}$ Department of Pharmaceutics, Mohamed Sathak AJ College of Pharmacy, Sholinganallur, \\ Chennai, Tamil Nadu, India \\ ${ }^{4}$ Department of Pharmaceutics, Periyar College of Pharmaceutical Sciences, Trichy, Tamil \\ Nadu, India
}

Received: 03-08-2021 / Revised Accepted: 29-08-2021 / Published: 01-09-2021

\begin{abstract}
The present study was carried out to formulate "Herbal Microsponges" by using "Ethanolic" extract of "Enicostemma axillare" leaves, to explore the drug release based on the type and concentration of "Polymers" used in the formulation. The extract was subjected to preliminary phytochemical screening which indicates the presence of Alkaloids and flavonoids. Isolation of flavonoids was done which consists anti arthritic activity. Microsponges were prepared and the evaluation studies of each formulation were compared. In the determination of encapsulation efficacy of microsponges, the ratio of polymer played an important role. Maximum encapsulation efficacy was observed with $100 \mathrm{mg}$ of polymer when used along with the drug in 1:1 ratio. Similarly, the concentration of emulsifier Poly Vinyl Alcohol (PVA) has a key role to play in the preparation of microsponges.
\end{abstract}

Key words: Herbal Microsponges, Ethanolic extract, Enicostemma axillare, Flavonoids, Polymers, PVA, Rheumatoid arthritis

\section{INTRODUCTION}

Arthritis is one of the leading causes of disability in aging humans. Arthritis (from Greek arthro-, joint +- it is, inflammation), as its name indicates, is a group of diseases that targets and attacks the articular joints of the body. Arthritis is a chronic, inflammatory, multisystem autoimmune disease. The individuals of any age can be affected with Arthritis; the usual age of onset is between 25 and

Address for Correspondence: Velmurugan T, Department of Pharmaceutics, Associate Professor, Mohamed Sathak AJ College of Pharmacy, Sholinganallur, Chennai, Tamil Nadu, India; E-mail: velmurugan.mpharm@gmail.com

How to Cite this Article: Velmurugan T, Muthu Lakshmi T, Reeta Vijayarani, Sundararajan, Santhasheela. Formulation and evaluation of herbal microsponge by using enicostemma axillare leaf ethanolic extract. World J Pharm Sci 2021; 9(9): 192-202.

This is an open access article distributed under the terms of the Creative Commons Attribution-NonCommercialShareAlike 4.0 International License, which allows adapt, share and build upon the work non-commercially, as long as the author is credited and the new creations are licensed under the identical terms. (cc) EY-NC-SA 
50 with a peak in the 40 s and 50s. At any given time approximately two million individuals in the US are affected by Rheumatoid Arthritis. In India also more than about $20 \%$ of total population is suffering from arthritis. Arthritis is due to the wearing down of cartilage, which cushions the ends of the bones which is depicted in following figure. The joints most commonly affected by arthritis are weight-bearing joints, such as feet, knees, hips, spine and other joints, such as finger and thumb joints ${ }^{2,3}$.

Risk factors of arthritis: The key risk factors includes age, gender, excess weight, injury and complications from other conditions, dietary pattern, consumption of excess alcohol, life style, heredity, hormonal factors, environmental factors and lack of physical activity ${ }^{4}$.

\section{Rheumatoid Arthritis ${ }^{5}$ \\ ARTHRITIC CHANGES AS COMPARED TO NORMAL PATTERN}

\section{NORMAL JOINT}

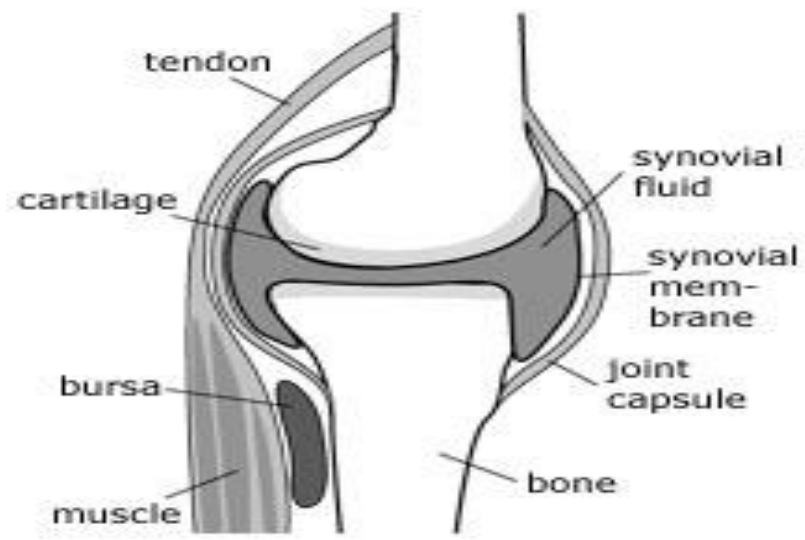

\section{ARTHRITIC JOINT}

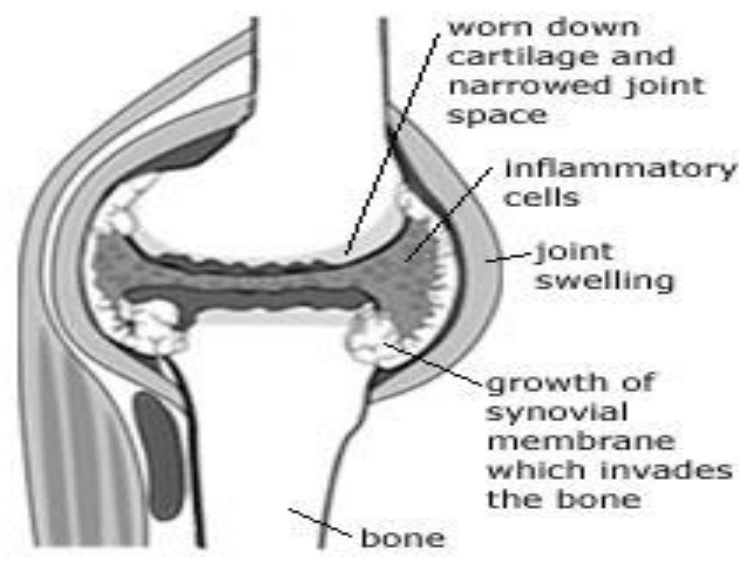

Cartilage - A tough material that cushions and protects the bone ends. The end of each bone is covered with cartilage. In osteoarthritis, there is a breakdown of cartilage. Rheumatoid arthritis (RA) is an inflammatory disease. It largely affects synovial joints, which are lined with a specialised tissue called synovium. RA typically affects the small joints of the hands and the feet, and usually both sides equally and symmetrically, although any synovial joint can be affected. It is a systemic disease and so can affect the whole body, including the heart, lungs and eyes. There are approximately 400,000 people with RA in the UK. The incidence of the condition is low, with around 1.5 men and 3.6 women developing RA per 10,000 people per year. This translates into approximately 12,000 people developing RA per year in the UK.

\section{MICROSPONGE DRUG DELIVERY SYSTEM (MDS)}

Microsponges are porous, polymeric microspheres that are used mostly for topical and recently for oral administration. Microsponges are microscopic spheres capable of absorbing skin secretions, therefore reducing oiliness and shine from the skin. Spherical particles composed of clusters of even tinier spheres are capable of holding four times their weight in skin secretions. The particle size ranges between 5-300 micrometer ${ }^{6}$.

Most liquid or soluble ingredients can be entrapped in the particles. Actives that can be entrapped in Microsponges must meet following requirements,

1. It should be either fully miscible in monomer or capable of being made miscible by

addition of small amount of a water immiscible solvent.

2. It should be water immiscible or at most only slightly soluble.

3. It should be inert to monomers.

4. It should be stable in contact with polymerization catalyst and conditions of polymerization.

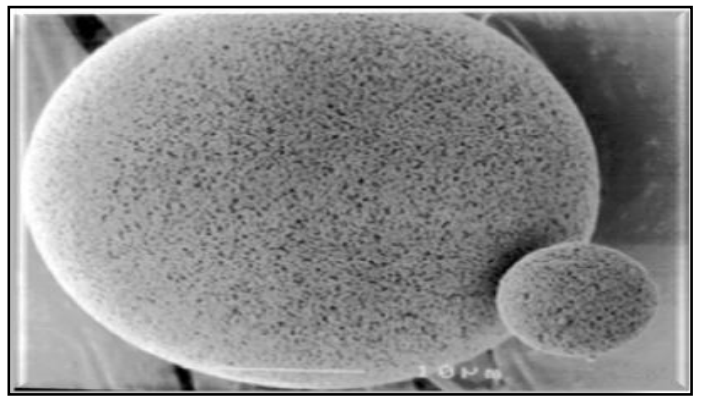

\section{MICROSPONGE}

Active following these criteria serves as porogen or pore forming agent. Such drugs can be entrapped while polymerization takes place by one-step process. While when the material is sensitive to the polymerization conditions, polymerization is performed using substitute porogen. The porogen is then removed and replaced by contact absorption assisted by solvents to enhance absorption rate. 
Release can be controlled through diffusion or other triggers such as moisture, $\mathrm{pH}$, friction, or temperature. This release technology is available for absorbent materials or to enhance product aesthetics. Microsponge delivery system can be incorporated into conventional dosage forms such as creams, lotions, gels, ointments, and powder and share a broad package of benefits. Systems can and improve its formulation flexibility. The most closely related systems are Microcapsules and Microspheres. Microcapsules are spherical particles containing an active agent in the core, surrounded by a polymeric membrane. Microspheres are spherical particles containing the active agent dispersed in a polymeric matrix. The major distinguishing feature between Microsponge and Polytrap systems and Microcapsules, or Microspheres, is structure of Microsponge and Polytrap systems are highly porous, while Microspheres or Microcapsules are solid particles with no internal voids.

A variety of active agents can be entrapped in a single Microsponge system and to release them at desired rates. The Microsponge system can prevent excessive accumulation of ingredients within the epidermis and the dermis. Potentially, the Microsponge system can reduce significantly the irritation of effective drugs without reducing their efficacy. Further these porous microspheres with active ingredients can be incorporated in to formulations such as creams, lotions and powders. Microsponges consisting of non-collapsible structures with porous surface through active ingredients are released in a controlled manner. This delivery system can be incorporated into conventional dosage forms such as creams, lotions, gels, ointments, and powder and share a broad package of benefits.

\section{Advantages of $\mathrm{MDS}^{7}$}

- Advance oil control-absorb up to 6 times its weight without drying

- Extended release- continuous action up to 12 hours

- Reduced irritation-better tolerance means broader consumer acceptance

- Improve product aesthetics-gives product an elegant feel

- Improve the stability-thermal, physical and chemical, Allow incorporation of immiscible

- Allow for novel product form, Improve the material processing

- Conversion of indigenous drugs in to Novel drug delivery system

\section{Preparation of Microsponges ${ }^{8}$}

Drug loading in microsponges can take place in two ways, one-step process or by two-step process; based on physico-chemical properties of drug to be loaded. If the drug is typically an inert non-polar material, will create the porous structure it is called porogen. Porogen drug, which neither hinders the polymerization nor become activated by it and stable to free radicals is entrapped with one-step process.

Liquid-liquid suspension polymerization: Microsponges are conveniently prepared by liquidliquid suspension polymerization. Polymerization of styrene or methyl methacrylate is carried out in round bottom flask. A solution of non-polar drug is made in the monomer, to which aqueous phase, usually containing surfactant and dispersant to promote suspension is added. Polymerization is effected, once suspension with the discrete droplets

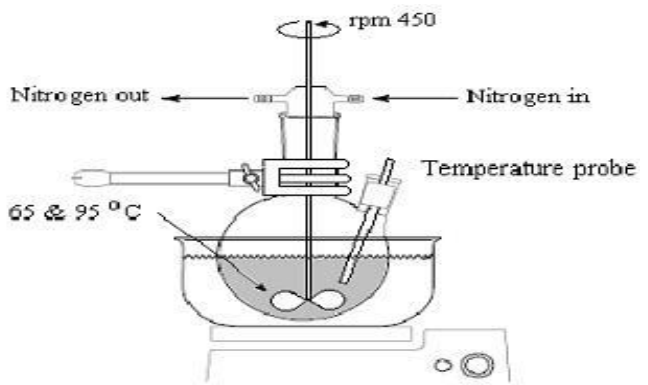

of the desired size is established; by activating the monomers either by catalysis or increased temperature.

\section{REACTION VESSEL FOR MICROSPONGE PREPARATION BY LIQUID-LIQUID SUSPENSION POLYMERIZATION}

When the drug is sensitive to the polymerization conditions, two-step process is used. The polymerization is performed using substitute porogen and is replaced by the functional substance under mild experimental conditions.

\section{Quasi-emulsion solvent diffusion ${ }^{9}$}

As explained in following figure, the microsponges can also be prepared by quasi-emulsion solvent diffusion method using the different polymer amounts. To prepare the inner phase, Eudragit RS 100 was dissolved in ethyl alcohol. Then, drug can be then added to solution and dissolved under ultrasonication at $35{ }^{\circ} \mathrm{C}$. The inner phase was poured into the PVA solution in water (outer phase). Following $60 \mathrm{~min}$ of stirring, the mixture is filtered to separate the microsponges. The microsponges are dried in an air-heated oven at 40 ${ }^{\circ} \mathrm{C}$ for $12 \mathrm{~h}$ and weighed to determine Production Yield (PY). 


\section{PREPARATION OF MICROSPONGES BY QUASI EMULSION SOLVENT DIFFUSION METHOD}

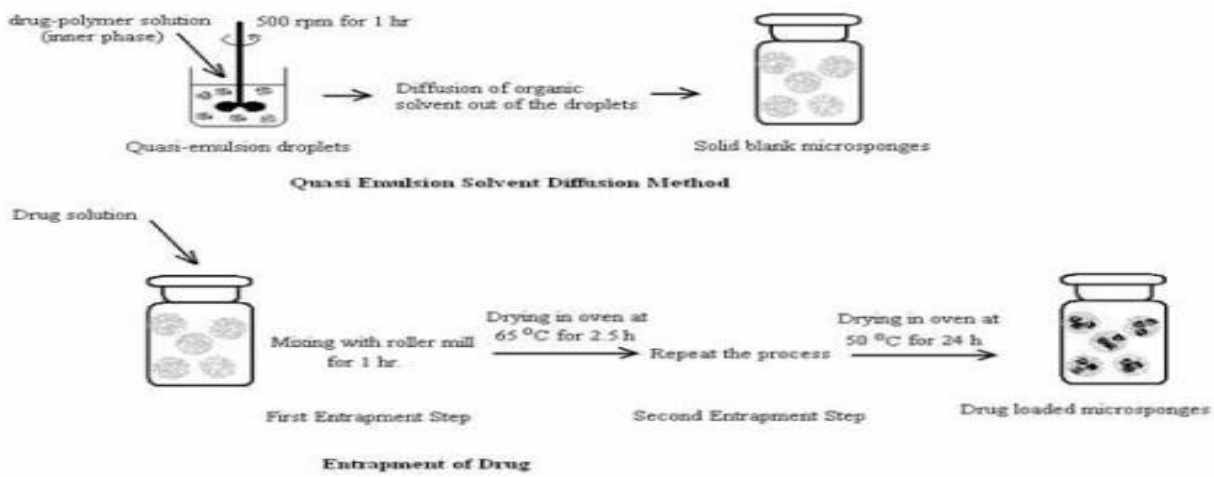

\section{PLANT PROFILE}

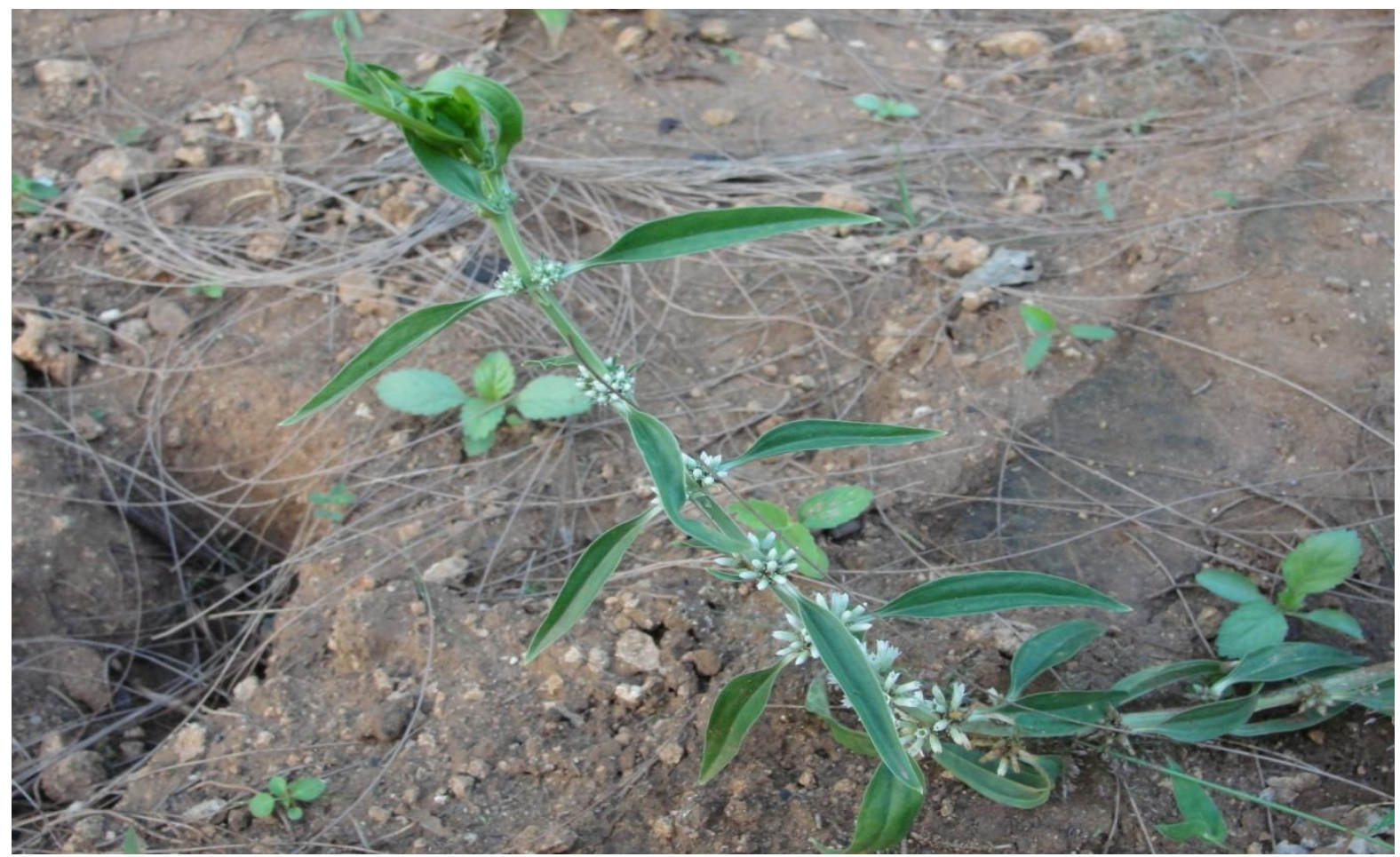

Enicostemma axillare is a perennial herb found throughout India and common in coastal areas. It is also called as Vellarugu in Tamil. The plant is used in folk medicine to treat diabetes mellitus, rheumatisum, abdominal ulcers, hernia, swelling, itching and insect poisoning, anti-inflammatory, hypoglycaemic and anticancer activities have been reported. The whole plant is used in medicine as digestive, anti-inflammatory, liver tonic, antimalarial, antipyretic and as a laxative. According to ayurvedic literature survey, the fresh juice of leaves has been used as a bitter tonic, to control arthritis, in typhoid fever and as cooling agent. The plant is traditionally used in the treatment of hepatic diseases and as a blood purifier. It also acts as ethnomedicine for snakebite. The plant paste is applied on boils. The leaves are fed to cattle to increase appetite ${ }^{10}$.

Botanical names $^{11}$ - Enicostemma axillare (Lam.)

A. Raynal

Family - Gentianaceae

Synonyms-Enicostemma littorale Blume A. Raynal Common names

Indian - Indian White head

Tamil- Vellarugu, Vallari, Arukumuli, Chakkiraviraiyanantan 
Hindi - Chota chirayata, Katvinayi,

Naame, Nahli, Nawari

\author{
Sanskrit - Mamajjakah, Nagajihva, Nahi \\ Kannada - Chikka chirrayuta \\ Malayalam - Vallari, Vellarugu \\ Telugu - Nelagolimidi, Nelagurugudu
}

\section{DETAILED DESCRIPTION OF PLANT}

Erect perennial herb, $5-30 \mathrm{~cm}$. Tall, simple or branched at the base. Stem cylintric, glabrous with a decurrent ridge below each leaf. Leaves sessile (sometimes narrowed into a petiole-like base), longer than the internodes; lamina (1)5-8 x 0.3-1 $\mathrm{cm}$., liner to lanceolate or narrowly oblong, entire, obtuse and mucronate at the apex, somewhat narrowing towards the base, 3-nerved from the base, glabrous. Inflorescence in many flowered axillary cluster, numerous in the axils of each pair of leaves. Flowers white with green lines, druying yellowish, sessile or subsessile; bracts long, shorter than the calyx, lanceolate - acuminate, carinate. Calyx tube 1-2 mm. Long; lobes uneual, 0.7-1.5(2) x 0.4-0.7 mm., triangular to lanceolate, acute at the apex and narrowly scarious at the margin. Corolla tube 3.5-6 mm. long; lobes 1.5-2 x 0.7-1 mm., ovate and abruptly narrowing to an acute or mucronate apex. Stamens inserted below the sinuses, just above the middle of the tube; filaments 1.5-2.3 mm. long, with a double hood at the insertion point; anthers. $1 \mathrm{~mm}$. long, erect, shortly apiculate. Ovary 5-6 x $1 \mathrm{~mm}$., ovoid; style 2-2.5 $\mathrm{mm}$. long, subulate; stigma subcapitate. Capsule 34.5 x 2- $2.5 \mathrm{~mm}$., obovoid. Seeds $0.4-0.5 \mathrm{~mm}$. in diam., subglobose, reticlulate faveolate.

\section{Medicinal use}

- Rheumatism

- Arthritis

- Stomachic, Bitter tonic, Anti-inflammatory, Antioxidant, Hypolipidemic, Hepatoprotective, Hypoglycemi, Anti-cancer, Abdominal-ulcer.

\section{MATERIAL AND METHODS:}

$\checkmark$ Collection of Plant (Leaf)

$\checkmark$ Extraction

$\checkmark$ Preformulation studies

$\checkmark \quad$ Phytochemical screening

$\checkmark$ Fabrication and characterization MDS

$\checkmark$ Evaluation study

\section{COLLECTION OF HERB}

The Herb Enicostemma axillare was collected from in and around Trichy, TamilNadu, India. The leaves were shade dried and powdered for extraction.

\section{EXTRACTIION ${ }^{12}$}

Extraction is the process of removing or extracting or separating of active constituents from the crude drugs by using suitable solvents such as water, alcohol, solvent ether etc. This is the basic principle involved in extraction process. The active ingredients that have been extracted from the crude drugs are known as extractives and the preparation so obtained are known as extracts.

Soxhlet extraction: The apparatus consists of boiling flask, soxhlet extractor and a condenser. The drug to be extracted is packed in a filter paper and placed in the extractor. The solvent is taken in the boiled flask. The flask is heated. The solvent is boiled and vapour arises from the solvent and enters in to the condenser through a side tube present in the condenser. The condensed hot liquid falls on the packed column of the drug and the active constituents are extracted. As more and more condensed solvent fall on the drug, the level of the solvent in the extractor and the syphon rises. When the level of the solvent reaches the top of the syphon the solvent along with dissolved active constituents drips back into the flask from the extractor through the syphon.

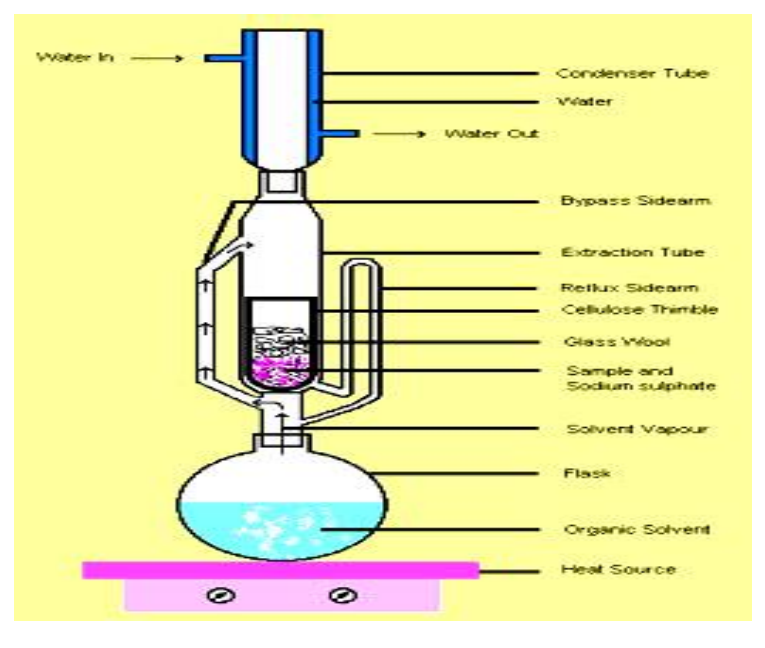

\section{SOXHLET EXTRACTION}

On further heating the vapours of the solvent arises from the flask while the soluble active constituent remains in it and the process is repeated. Every time the solvent drips into the flask from the extractor, the solvent carries more and more active constituent. The same process is repeated again and again until all the active constituents are extracted.

\section{Extraction for leaf extract}

$100 \mathrm{gm}$ of crude powder of leaves of Enicostemma axillare were extracted with ethanol under 60 to $80^{\circ} \mathrm{C}$ by continuous hot percolation process using Soxhlet apparatus. After completion of extraction. The solvent was removed by distillation under reduced pressure. Brown residue was obtained. The residue is then stored in a desiccators.

\section{PREFORMULATION STUDIES \\ Phytochemical screening \\ Drug identification}


IR spectra and Absorption maxima identified the crude extract of Enicostemma axillare. [I.P (Indian Pharmacopeia) 1996].

\section{Identification of Plant Constituents by Preliminary Phytochemical Tests ${ }^{13}$ \\ The powdered drug of the plant Enicostemma axillare was subjected to phytochemical tests for identification of its active constituents.}

Test for Alkaloids: A small portion of solvent free extracts were stirred separately with few drops of dilute hydrochloric acid and filtered \& tested carefully with various alkaloidal reagents

Mayer's reagent - Cream precipitate

Dragendroff's reagent - Orange brown precipitate

Hager's reagent - $\quad$ Yellow precipitate

Wagner's reagent - Reddish brown precipitate

\section{Test for Carbohydrates \& Glycosides}

The minimum amount of extracts were dissolved in $5 \mathrm{ml}$ of distilled water $\&$ filtered. The filtrate was subjected to test for carbohydrates \& glycosides.

\section{Molisch's test}

The filtrate was treated with 2-3 drops of $1 \%$ alcoholic alpha naphthol \& $2 \mathrm{ml}$ concentrated sulphuric acid was added along the sides of test tube. Violet ring was observed at the junction of 2 layers which showed the presence of carbohydrate.

\section{Legal's test}

To the hydrolysate $1 \mathrm{ml}$ of sodium nitroprusside solution was added \& then it was made alkaline with sodium nitroprusside. Pink colour was not produced which indicated of the absence of glycosides.

Borntrager's test Hydrolysate was treated with chloroform and the chloroform layer was separated. To this equal quantity of dilute ammonia solution was added. No colour change in ammonical layer was observed.

\section{Test for Flavonoids}

a) With aqueous sodium hydroxide solution - blue to violet colour (Anthocyanins); yellow colour (Flavones); yellow to orange colour (Flavonones)

b) With concentrated sulphuric acid - yellowish orange colour (Anthocyanins); yellow to orange colour (Flavones); orange to crimson (Flavonones)

c) Shinoda's test Test

extracts were dissolved in alcohol, to that piece of magnesium turnings followed by concentrated hydrochloric acid were added drop wise and heated. Appearance of magenta colour showed the presence of flavonoids.

\section{d) Test for Phytosterol}

$1 \mathrm{~g}$ of different extracts were dissolved in few drops of dilute acetic acid; $3 \mathrm{ml}$ of acetic anhydride was added followed by few drops of concentrated sulphuric acid. Appearance of bluish green colour showed the presence of phytosterol.

\section{Test for Fixed Oil \& Fats}

Small quantities of various extracts were separately pressed between two filter papers. No oil stain on the paper indicated the absence of fixed oil.

Few drops of $0.5 \mathrm{~N}$ alcoholic potassium hydroxide were added to small quantity of various extracts along with a drop of phenolphthalein. Mixture was heated on water bath for 1-2 hours. No soap formation, neutralization of alkali indicated the absence of fixed oil and fats.

\section{Test for Saponins}

The extracts were diluted with $20 \mathrm{ml}$ of distilled water and it was agitated on graduated cylinder for 15 minutes. The presence of saponins was indicated by formation of $1 \mathrm{~cm}$ layer of foam.

\section{Test for Tannins and Phenolic Compounds}

Small quantities of various extracts were taken separately in water and tested for presence of phenolic compounds and treated with

1) Dilute ferric chloride solution (5\%) - violet colour

2) $1 \%$ sodium gelatin containing $10 \%$ sodium chloride - white precipitate

3) $10 \%$ lead acetate solution - white precipitate

\section{Test for Proteins and Free Amino Acids}

Dissolved small quantities of various extracts in few $\mathrm{ml}$ of water and treated with.

1. Millon's reagent - Red colour showed the presence of proteins and free amino acids

2. Ninhydrin reagent - Purple colour showed the presence of proteins and free amino acids.

3. Biuret test - Equal volume of 5\% solution and $1 \%$ copper sulphate solutions were added. Appearance of purple colour showed the presence of proteins and free amino acids.

\section{FABRICATION AND CHARACTERIZATION OF MDS}

The microsponges were prepared by quasi emulsion solvent diffusion method. In this method, the organic internal phase containing extract of Enicostemma axillare (100mg) and ethyl cellulose in $20 \mathrm{ml}$ dichloromethane was gradually added into $60 \mathrm{ml}$ distilled water which contained different concentration (0-2\%) of poly vinyl alcohol (PVA) as emulsifying agent. The mixture was stirred for 6 
hours, at $25{ }^{\circ} \mathrm{C}$. The formed microsponges were filtered and washed with distilled water before being tray-dried at room temperature. For the evaluation of the effect of drug: polymer ratio on the physical characteristics of microsponges, different weight ratios of drug to Ethyl Cellulose (EC) $(1: 0.5,1: 1,1: 1.5)$ were employed. In all these formulations, the total amount of drug was kept constant. To optimize the particle size, size distribution and the drug release from the microsponges, an individual formulation was selected and a series of the microsponges were prepared using different stirring rates. However, for optimizing the preparation method and the characteristics of the prepared microsponges were evaluated ${ }^{9}$.

\section{Optimization of various parameters}

During the microsponges preparations, variables such as amount of polymer, emulsification agent, stirring time, and stirring speed were optimized for getting spherical shape Microsponge with maximum drug encapsulation efficacy.

\section{Determination of encapsulation efficacy}

$1 \mathrm{gm}$ of microsponge was dispersed in $100 \mathrm{ml}$ ethanol and the solution containing extract of Enicostemma axillare was filtered through the Whatman filter paper No.40. The absorbance of the solution was measured by UV spectrophotometer (Shimadzu 1700) at $286 \mathrm{~nm}$ against blank to determine its encapsulation efficacy. The encapsulation efficacy of microsponge was calculated according to the following equation.

$$
\text { Encapsulation efficacy }=\frac{\text { Actual drug content in microsponge }}{\text { Theoretical drug content }} \text { X100 }
$$

\section{Particle size determination ${ }^{14}$}

Free flowing powders with fine aesthetic attributes are possible to obtain by controlling the size of particles during polymerization. Particle size analysis of loaded and unloaded microsponges can be performed by laser light diffractometry or other

\section{Absorption Maxima}

suitable method. The values (d50) can be expressed for all formulations as mean size range.

Scanning Electron Microscope (SEM) study: The three prepared microsponges (MDS 1, MDS 2 and MDS 3) were subject to Scanning Electron Microscopy (SEM) studies. The morphology of microsponge (size and shape) was examined with SEM (Hitachi model S-3000H, Japan) operating at $15 \mathrm{kv}$. The samples were mounted on a metal stub with double adhesive tape and coated with gold palladium alloy under vacuum.

\section{Compatibility study}

The above three formulation of drug loaded microsponges were subject to Infra Reds Spectroscopy study to find out any interaction between the drug and polymer. The IR-peaks of drug and placebo microsponges were also taken for the compatibility study.

\section{Drug content}

A specific quantity (1 $\mathrm{gm})$ of microsponge was dispersed in $100 \mathrm{ml}$ phosphate buffer $(\mathrm{pH} 7.4)$ and the solution containing extract of Enicostemma axillare was filtered through the whatman filter paper No.40. The absorbance of the solution was measured by UV spectrophotometer (Shimadzu 1700) at $286 \mathrm{~nm}$ against blank to determine its drug content.

\section{RESULTS AND DISCUSSION}

Extraction of leaf of enicostemma axillare: Ethanolic extraction of leaf of Enicostemma axillare was carried out as per the procedure described in 7.3.and yield of the extract was $2.1 \% \mathrm{w} / \mathrm{w}$

Identification and characterization of extract of enicostemma axillare

Ultra Violet spectrophotometry: The extraction of Enicostemma axillare exhibits maxima at 286 $\mathrm{nm}$. Therefore, all the further measurements were taken at $286 \mathrm{~nm}$.

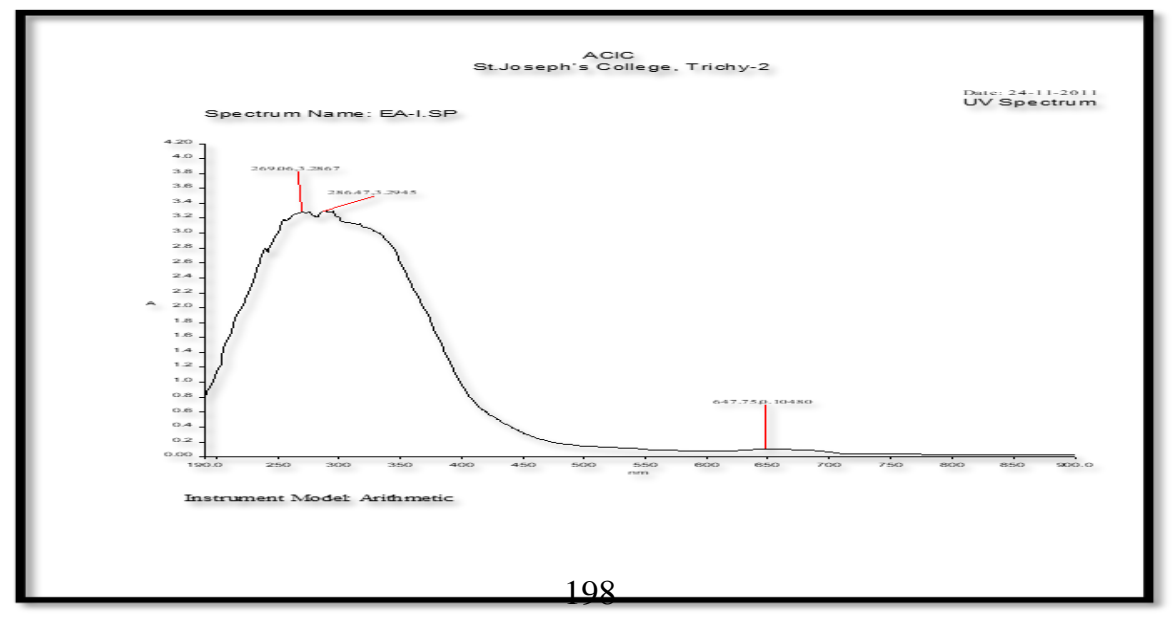


The absorption maxima of plant extract was found at $286 \mathrm{~nm}$. This absorption maxima was compared with absorption maxima of isolated compound of swertiamarin from Enicostemma axillare [The collected extract $\lambda$-max is near to $\lambda$-max of swertiamarin]. This confirms the extract contains the flavonoid-swertiamarin which responsible for anti arthritic activity.

PREFORMULATION STUDIES: CHEMICAL TESTS OF ENICOSTEMMA AXILLARE

\begin{tabular}{|l|l|l|l|}
\hline S.No & Plant constituents & Test/reagent & $\begin{array}{l}\text { Ethanolic } \\
\text { extract }\end{array}$ \\
\hline 1 & Steroids & Salkovaski & -- \\
\hline 2 & Alkaloids & & \\
\hline & & Dragendroff's & + \\
\hline & & Hager's test & + \\
\hline & & Mayer's test & + \\
\hline & & Wagner'stest & + \\
\hline 3 & Saponin & Foams test & ++ \\
\hline & & Haemolysis test & ++ \\
\hline 4 & Fat and oils & Filter paper test & -- \\
\hline 5 & Tanins and phenolic & Ferric chloride test & ++ \\
\hline & & Lead acetate test & ++ \\
\hline & & Pot.Dichromate & ++ \\
\hline & & Bromine water & ++ \\
\hline 6 & Flavonoids & Shinoda test & ++ \\
\hline & & Lead acetate test & ++ \\
\hline 7 & Corbohydrates & Molisch test & ++ \\
\hline & & Fehling's test & ++ \\
\hline & & Barfoed's test & ++ \\
\hline 8 & Protiens & Millon's test & ++ \\
\hline & & Biuret test & ++ \\
\hline 9 & Amino acid test & Ninhydrine test & ++ \\
\hline
\end{tabular}

1. Alkaloid - Hager's test, Mayer's test, Wagner's test $^{15}$ - Present

2. Flavonoid - Shinoda test, Lead acetate test ${ }^{15}$ Present

Inference It showed presence of alkaloids and flavonoids. It confirms the extract of Enicostemma axillare contains Alkaloids and Flavonoids.

Solubility studies

The solubility of extract of Enicostemma axillare in various solvents are follows

Solubility of extract of Enicostemma axillare

Solubility

Solvent

\begin{tabular}{|l|l|}
\hline Very soluble & $\begin{array}{l}\text { chloroform, Ethyl } \\
\text { acetate }\end{array}$ \\
\hline Soluble & $\begin{array}{l}\text { ethanol (95\%), } \\
\text { Dichloromethane(DCM) }\end{array}$ \\
\hline $\begin{array}{l}\text { Practically } \\
\text { insoluble }\end{array}$ & light petroleum \\
\hline
\end{tabular}

\section{$\begin{array}{lll}\text { RESULTS OF OPTIMIZATION } & \text { OF }\end{array}$ PARAMETERS}

Three batches of extract of Enicostemma axillare microsponges namely, MDS 1, MDS 2, MDS 3 were prepared as per the procedure described in the table and were optimized as per the following formula and process variables given in the table 


\begin{tabular}{|c|c|c|c|c|c|c|}
\hline Process variables & $\begin{array}{l}\text { Drug } \\
\text { (mg) }\end{array}$ & $\begin{array}{l}\text { Polymer } \\
\text { (mg) }\end{array}$ & $\begin{array}{l}\text { PVA } \\
(\%)\end{array}$ & $\begin{array}{l}\text { Stirring } \\
\text { Time } \\
\text { (hours) } \\
\end{array}$ & $\begin{array}{l}\text { Stirring } \\
\text { Speed } \\
(\text { rpm }) \\
\end{array}$ & $\begin{array}{l}\text { Encapsulation } \\
\text { efficacy } \\
\pm \text { S.D. }(\%) \\
\end{array}$ \\
\hline \multirow[t]{3}{*}{ Polymer (EC) } & 100 & 50 & 2 & 6 & 4000 & $55.14 \pm 1.62$ \\
\hline & 100 & $100 *$ & 2 & 6 & 4000 & $76.22 \pm 0.42$ \\
\hline & 100 & 150 & 2 & 6 & 4000 & $61.78 \pm 1.82$ \\
\hline \multirow{3}{*}{$\begin{array}{l}\text { Emulsification } \\
\text { agent (PVA) }\end{array}$} & 100 & 100 & Nil & 6 & 4000 & $35.72 \pm 2.60$ \\
\hline & 100 & 100 & 1 & 6 & 4000 & $47.30 \pm 0.89$ \\
\hline & 100 & 100 & $2 *$ & 6 & 4000 & $76.22 \pm 0.42$ \\
\hline \multirow[t]{3}{*}{ Stirring time } & 100 & 100 & 2 & 2 & 4000 & $56.75 \pm 1.32$ \\
\hline & 100 & 100 & 2 & 4 & 4000 & $58.20 \pm 0.61$ \\
\hline & 100 & 100 & 2 & 6* & 4000 & $76.22 \pm 0.42$ \\
\hline \multirow[t]{3}{*}{ Stirring speed } & 100 & 100 & 2 & 6 & 2000 & $49.46 \pm 0.23$ \\
\hline & 100 & 100 & 2 & 6 & 4000* & $76.22 \pm 0.42$ \\
\hline & 100 & 100 & 2 & 6 & 6000 & $33.24 \pm 0.88$ \\
\hline
\end{tabular}

OPTIMIZATION PARAMETERS

* Optimum parameter, the values are mean $\pm \mathrm{SD}(\mathrm{n}=3)$

From the above results MDS 2 was optimized by considering the various optimization parameters as shown in the following table

\begin{tabular}{|l|l|l|l|l|l|}
\hline $\begin{array}{l}\text { Formulation } \\
\text { Code }\end{array}$ & $\begin{array}{l}\text { Polymer } \\
\text { concentration } \\
\text { (mg) }\end{array}$ & $\begin{array}{l}\text { Drug } \\
\text { concentration } \\
\text { (mg) }\end{array}$ & $\begin{array}{l}\text { Stirring } \\
\text { speed } \\
\text { (rpm) }\end{array}$ & $\begin{array}{l}\text { Stirring } \\
\text { time } \\
\text { (hours) }\end{array}$ & $\begin{array}{l}\text { Encapsulation } \\
\text { efficacy } \pm \text { S.D(\%) }\end{array}$ \\
\hline MDS 2 & 100 & 100 & 4000 & 6 & $76.22 \pm 0.42$ \\
\hline
\end{tabular}

\section{OPTIMIZED PARAMETERS}

The values are mean \pm S.D $(n=3)$

Effect of polymer on encapsulation efficacy of drug: The quantity of polymer used in the preparation was 50 to $150 \mathrm{mg}$. The encapsulation efficacy was high with $100 \mathrm{mg}$ of polymer and desired size was obtained. The results showed that the ratio of polymer played an important role in the encapsulation efficacy of microsponges. It was found that by increasing the drug: polymer ratio, the mean particle size was increasing from 5 to 20 $\mu \mathrm{m}$ and encapsulation efficacy was also high with 1:1 drug polymer ratio. However further increase in the polymer concentration (1:1.5) had no proportionate increase in percentage of encapsulation efficacy, it may due to approaching system saturation. Hence, maximum encapsulation efficacy was observed with $100 \mathrm{mg}$ of polymer when used along with the drug in 1:1 ratio.

Effect of emulsifying agent on encapsulation efficacy of drug: The concentration of emulsifier (PVA) has a key role to play in the preparation of microsponges. When the concentration of emulsifier was increased from 1 to $2 \%$, the drug encapsulation efficacy also increased. Hence, maximum encapsulation efficacy was observed with $2 \%$ of emulsifier (PVA). At 4000rpm, the Microsponges were produced of desired range with maximum encapsulation efficacy. At 2000rpm, the Microsponges were not in uniform size and encapsulation efficacy was also less. At 6000rpm, the particle size was small with low encapsulation efficacy. The stirring time was optimized to get desired shape and higher encapsulation efficacy. The optimized stirring time was 6 hours.

\section{COMPATIBILITY STUDY}

Compatibility study was accessed by Infra red spectroscopy (IR). The results are shown, The peak for drug, peak for placebo microsponges and peak for drug loaded microsponges. There was no change in the IR peaks. Thus it confirms that there is no interaction between the drug and polymer.

\begin{tabular}{|l|l|l|}
\hline S.No & Formulation Code & Mean Diameter in $\boldsymbol{\mu m}$ \\
\hline 1 & MDS 1 & 33 \\
\hline 2 & MDS 2 & 36 \\
\hline 3 & MDS 3 & 31 \\
\hline
\end{tabular}


PARTICLE SIZE DETERMINATION

Particle sizes were analysed. Mean particles size ranged from 31 to $36 \mu \mathrm{m}$. These particle size ranges are preferred to use topical formulation.

\section{MORPHOLOGICAL STUDY}

Scanning Electron Microscope (SEM) study: Three batches namely MDS 1, MDS 2 and MDS 3 were subject to SEM studies, the results indicated that the formulation MDS 2 are in spherical, discrete particle with internal voids with a size range of 5 to $40 \mu \mathrm{m}$.

SEM PHOTOGRAPHY OF MDS 1(1:0.5)

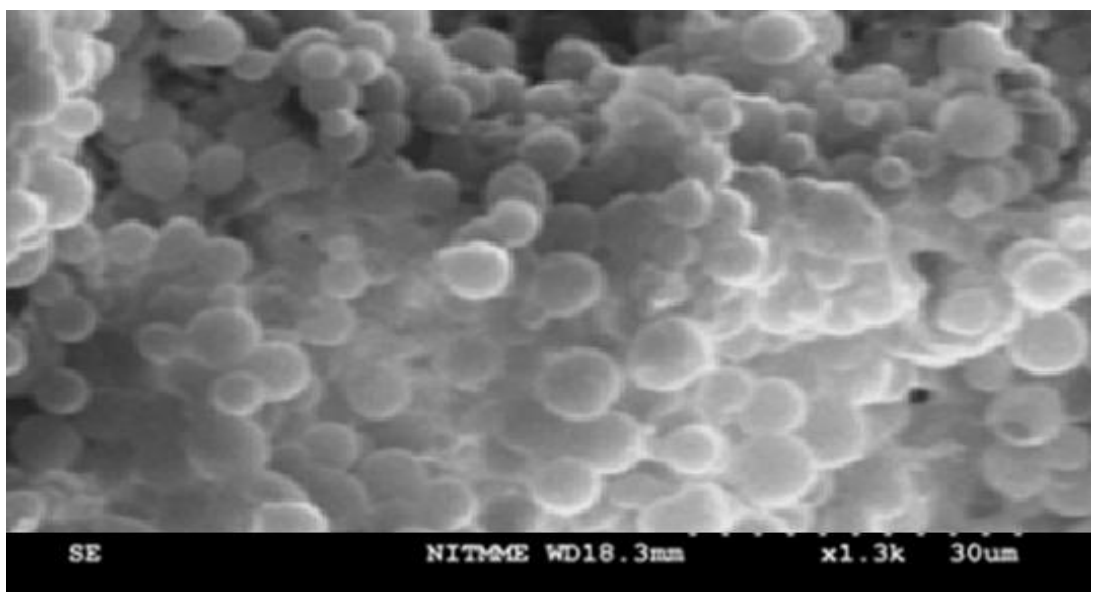

SEM PHOTOGRAPHY OF MDS 2(1:1)
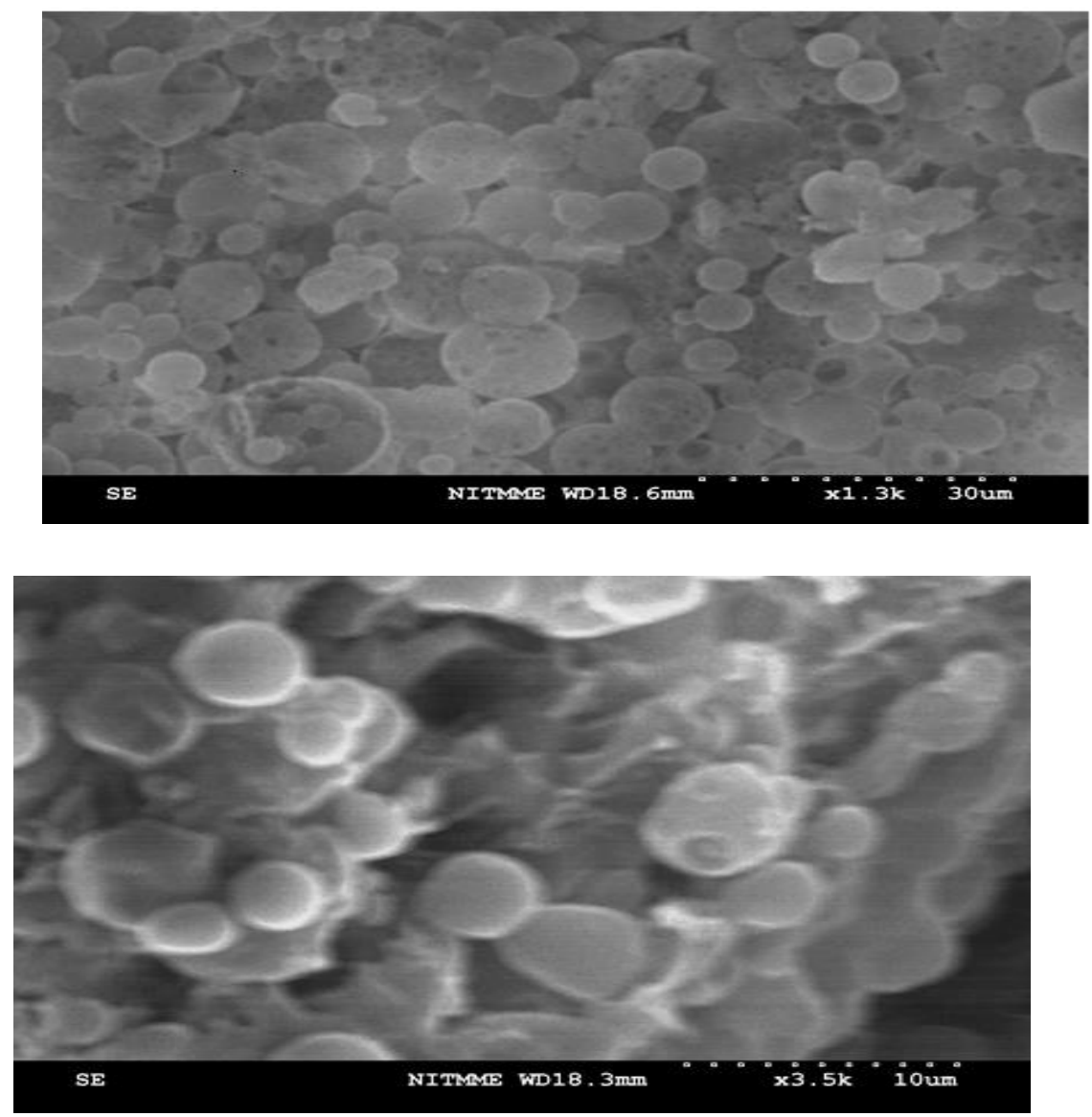

SEM PHOTOGRAPHY OF MDS 3(1:1.5) 


\section{DRUG CONTENT}

The drug content of the formulation was estimated and result of MDS 2 is $92.04 \%$. The result indicated that the drug content is more in MDS 2 formulation.

\section{CONCLUSION}

Based on the literature survey, dried leaves of Enicostemma axillare the herb was selected for the research work. Ethanolic extraction of leaf was carried out as per the procedure and the yield of the extract was $2.1 \%$ w/w. The extract of Enicostemma axillare was identified and subjected to UV, FTIR studies. From the strong and characteristic peak obtained from FTIR confirm the functional group present (Flavonoids). As a part of the Preformulation study, the crude extract was subjected to qualitative chemical test and solubility studies and these tests confirm the presence of Alkaloids and Flavonoids. The microsponges were prepared by quasi emulsion solvent diffusion technique. For the purpose of optimization of the formulation of extract of Enicostemma axillare loaded Microsponge namely MDS 1, MDS 2 and MDS 3 were prepared by using different proportion of the drug:polymer ratio $(1: 0.5,1: 1,1: 1.5)$. In all these formulations, different amount of polymer
(50,100 and 150), emulsifying agent (0.1 and 2\%), stirring rate $(2000,4000$, and $6000 \mathrm{rpm})$ and stirring time (2, 4 and $6 \mathrm{hrs}$ ) were used and the amount of drug was kept constant for all batches. The formulation MDS 2 was optimized by considering the various above optimization parameters.

In the determination of encapsulation efficacy of microsponges, the ratio of polymer played an important role. Maximum encapsulation efficacy was observed with $100 \mathrm{mg}$ of polymer when used along with the drug in $1: 1$ ratio. Similarly, the concentration of emulsifier Poly Vinyl Alcohol (PVA) has a key role to play in the preparation of microsponges. When the concentration of emulsifier was increased from 1 to $2 \%$, the drug encapsulation efficacy also increased. Hence, maximum encapsulation efficacy was observed with $2 \%$ of emulsifier (PVA). The above three batches of extract of Enicostemma axillare loaded microsponges were subjected to SEM studies. The results indicated that the formulation MDS 2 exhibited spherical, discrete particle, with internal voids with a size ranging from 5 to $40 \mu \mathrm{m}$ when compared with other two batches.

\section{BIBLIOGRAPHY}

1. Sunetra K Patwardhan, Kaumudee Bodas, Sameer S Gundewar, Coping with Arthritis using safer herbal options International Journal of pharmacy and pharmaceutical sciences, issue 1,2010; vol 2.

2. Strange CJ. Coping with Arthritis in Its Many Forms. FDA Consumer, U.S.A-FDA, Publication No. (FDA) 1996; P 97-123

3. http://www.cdc.gov/arthritis/

4. Arthritis Info-sheet for seniors. The Arthritis Society, Canada: Minister of Public Works and Government Services; 2000; (Reprint, Nov. 2005).

5. Walker R, Edward C. Clinical Pharmacy and Therapeutics. 3rd ed. London: Churchill Livingstone; 2003; (791-794, 797,804-806, 813-815).

6. Vyas S. and Khar R.K, Controlled Drug Delivery - Concept and Advances, $1^{\text {st }}$ Edn,Vallabh Prakashan, CBS Publication, New Delhi, 2002;(418-422p).

7. Patel, Geeta Patel, J.K, Pharmaceutical Processing, 2006.

8. Won R., United States Patent No. $(5,145,675)$ Two step method for preparation of controlled release formulations 1992.

9. Jelvehgari M, M.R. Siahi-Shadbad, S. Azarmi, Gary P. Martin and Ali Nokhodchi, The microsponge delivery system of benzoyl peroxide: Preparation, characterization and release studies, Int. J. Pharm, 2006; $308:(124-132)$.

10. V.N.Gite. Hepatoprodective activity of Enicostemma axillare in Carbon Tetrachloride induced HepatoToxicity in Albino Rats. International Research Journal RNI:RAJBIL 2009/30097 Vol. 1 Issue-7

11. Medicinal Plants in India by T.Pullaiah,2002; Vol.2 pp (234-235)

12. K. Sambamurthy, Pharmaceutical Engineering, $1^{\text {st }}$ Edition, New age international Publishers, 1998; P $(173,187)$.

13. Kokate CK. Practical Pharmacognosy, $1^{\text {st }}$ edition. VallabhPrakashan 1,New Delhi,1986; (15-30).

14. Parthiban K.G., Microsponge Role in Novel Drug Delivery System. International Journal of Pharmaceutical Research and Development (IJPRD) Vol. 3(4) June (2011) (117-125)

15. V.N.Gite. Evaluation of Physicochemical Standardization Parameters of Enicostemma axillare. J Biosci Tech, Vol 1 (4), 2010; (187-190). 